Review Article

\title{
Excellent Outcome of Psychosis Induced by Methamphetamine Intoxication after 20 Sessions of Electro Convulsive Therapy
}

\author{
Jamshid Ahmadi \\ Substance Abuse Research Center, Shiraz University of Medical Sciences, Shiraz, Iran
}

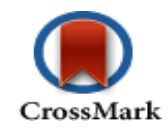

*Corresponding author: Jamshid Ahmadi, MD, Professor of Psychiatry, Founder and Director, Substance Abuse Research Center, Shiraz University of Medical Sciences, Shiraz, Iran, E-mail: Jamshid_Ahmadi@yahoo.com

\begin{abstract}
Severe psychosis induced by methamphetamine abuse is a growing problem in the world. We report the usefulness of Electro Convulsive Therapy (ECT) as an alternative option in the management of methamphetamine psychosis. Our findings indicated that ECT was beneficially employed in the treatment of severe methamphetamine psychosis. This case illustrates although medications could be effective in treating methamphetamine psychosis, however, ECT is more useful and also faster than medications. This is an interesting result. In addition to our understanding we might say that ECT could be an appropriate option in the treatment of methamphetamine psychosis, therefore this experience of an Iranian patient could add innovative information to the literature.
\end{abstract}

Keywords: Psychosis; Methamphetamine; ECT
Received Date: November 4, 2015

Accepted Date: November 30, 2015

Published Date: December 5, 2015

Citation: Ahmadi, J. Excellent Outcome of Psychosis Induced by Methamphetamine Intoxication After 20 Sessions of Electro Convulsive Therapy. (2015) J Addict Depend 1(2): 35- 36.

DOI: $10.15436 / 2471-061 X-15.011$

\section{Introduction}

In recent decades policy makers, health authorities and researchers have expended more time and attention to the epidemiology, prevention and treatment of mental disorders ${ }^{[1-3]}$ including addictions, especially stimulants abuse ${ }^{[4-5]}$.

In Iran health decision makers and also researchers pay more attention tomental problems and substance related disorders specially methamphetamine and other amphetamine derivatives ${ }^{[6,19]}$.

In the past years, methamphetamine was illegally smuggled in from the west countries, but now it is synthesized illegally in Iran in 'underground' laboratories. We should stress that the methamphetamine synthesized illegally in Iran has higher potency. Methamphetamine produces a common and ordinary state of well being accompanied by raised energy, physical activity and wakefulness $^{[20]}$. Prolonged use often ends to driven drug abuse, long-term health consequences, severe dependency, decreased weight, memory deficits, unstable affect, dysregulated mood, increased aggression, poor concentration, increased violence, hallucinations, delusions, and poor impulse control ${ }^{[20,21]}$.

Methamphetamine is abused globally. In the United States, 18 million people over age 12 have tried methamphetamine during their life ${ }^{[20]}$. As with any abused substance, meth addiction is a chronic relapsing disorder meriting the need for effective pharmacotherapies to aid the prevention of relapse.

Now we are going to report our patient with the diagnosis of psychosis induced by methamphetamine intoxication who responded to 20 sessions of ECT. $1 y^{[24,25,26]}$.

Indications of ECT in psychotic conditions ${ }^{[22,23]}$ and in methamphetamine induced psychosis have been reported previous-

\section{Patient Presentation}

Mr. M.K.Z. was a 27 year old single man, unemployed, graduated from high school, living with his parents in Shiraz city of Fars province in southern Iran. MKZ has been using opioids and benzodiazepines, and also smoking of methamphetamine since five years Prior To Admission (PTA) and several months later developed anxiety, depression, insomnia and restlessness. Since one month PTA, he developed severe agitation, restlessness, suicidal attempts, insomnia, low appetite, aggressive behaviors, hyperactivity, loquaciousness, and persecutory delusions.

He was brought to the emergency room of Ebnesina hospital. Then was admitted in dual diagnosis ward with the impression of methamphetamine induced psychosis with onset during intoxication. At the time of admission complete physical and

Copyrights: (C) 2015 Ahmadi, J. This is an Open access article distributed under the terms of Creative Commons Attribution 4.0 International License. 
neurological examinations were carried out. Laboratory tests including screening tests for HIV and hepatitis were done which were normal. Based on urine drug screening tests and also personal history he was smoking methamphetamine before hospital admission. Na valproate with dose of $400 \mathrm{mg} / \mathrm{d}$, olanzapine with dose of $10 \mathrm{mg} / \mathrm{d}$ was started. After 8 days of admission and due to lack of response to medications and also serious condition of the patient, double ECT (2 ECT sessions in the same anesthesia session) was started. After the tenth ECT, some of the symptoms such as insomnia, restlessness, agitation and delusions improved. After the sixteenth ECT patient was much better and after the twentieth ECT, patient was discharged.

Patient received bilateral ECT in the even days of the week only (Saturday, Monday, and Wednesday). Although patient did not receive optimum therapeutic dose and duration of antipsychotic medications(due to serious and emergency condition of the patient, we could not wait for more time and had to start double ECT), however, according to our daily precise monitoring and interview, patient improvement was due to ECT.

\section{Discussion}

Patient had no previous history of psychosis prior to substance abuse and had no family history of psychosis. Onset of psychotic symptoms was due to chronic consumption of methamphetamine only. Patient's family reported period of abstinences from substances in the past. Abstinence from substance had some improvement in symptoms, therefore, possibility of independent psychosis can be ruled out.

This case indicates ECT is very helpful in treating psychosis induced by methamphetamine intoxication. ECT use in psychotic conditions in general ${ }^{[22,23]}$ and in methamphetamine psychosis in particular have been reported previously ${ }^{[24,25,26]}$. However, a systematic prospective trial of ECT especially in refractory methamphetamine induced psychosis is yet to be published, and this case study is a considerable addition to the literature. It is of interest that double ECT continues to be used with good results in serious conditions. We followed the patient for 5 months. He did not report any symptoms of relapse yet.

\section{Conclusion}

ECT was practically employed in the treatment of methamphetamine psychosis. We might say that ECT could be a good option in the treatment ofmethamphetamine psychosis, therefore this case-study could illustrates an innovative information.

\section{Conflict of Interests: None to be declared.}

\section{References}

1. Mackay-Smith, M., Ahmadi, J., Pridmore, S. Suicide In Shooting Galleries. (2015) ASEAN Journal of Psychiatry16(1): 50-56.

2. Ahmadi, J., Ahmadi, N., Soltani, F., et al. Gender differences in depression scores of Iranian and German medical students. (2014) Iran J Psychiatry Behav Sci 8(4): 70-73.

3. Mani, A., Dastgheib, S.A., Chanoor, A., et al. Sleep Quality among Patients with Mild Traumatic Brain Injury: A Cross-Sectional Study.

Ommega Online Publishers

Journal Title: Journal of Addiction and Dependence(JAD)

Journal Short Name: J Addict Depend
(2015) Bull Emerg Trauma 3(3): 93-96.

4. Ahmadi, J., Kampman, K., Dackis, C. Outcome predictors in cocaine dependence treatment trials. (2006) Am J Addict 15(6): 434-439.

5. Ahmadi, J., Kampman, K., Osline, D.M., et al. Predictors of Treatment Outcome in Outpatient Cocaine and Alcohol Dependence Treatment. (2009) Am J Addict 18(1): 81-86.

6. Ahmadi, J., Kampman, K., Dackis, C., et al. Cocaine withdrawal symptoms identify "Type B" cocaine-dependent patients. (2008) Am J Addict 17(1): 60-64.

7. Ahmadi, J., Keshtkar, M., Pridmore, S. Methamphetamine Induced Synesthesia: A Case Report. (2011) Am J Addict 20(3): 306.

8. Ahmadi, J., Soltani, F., Tabatabaee, F., et al. Substance Use Disorders in Patients with Lung or Heart Diseases. (2014) Sch. J. App. Med. Sci 2(1A): 111-120.

9. Ahmadi, J., Maharlooy, N., Alishahi, M. Substance abuse: prevalence in a sample of nursing students. J Clin Nurs 2004 13(1): 60-64.

10. Ahmadi, J., Hasani, M. Prevalence of substance use among Iranian high school students. (2003) Addict Behav 28(2): 375-379.

11. Ahmadi, J., Benrazavi, L. Substance use among Iranian physical patients. (2002) The International Journal of Drug Policy 13(6): 505-506. 12. Ahmadi, J., Ostovan, M. Substance use among Iranian male students. (2002) The International Journal of Drug Policy 13(6): 511-512. 13. Ahmadi, J., Sharifi, M. Lifetime and Current Prevalence of Tobacco Smoking. (2013) J Addict Res Ther 4: 145.

14. Ahmadi, J., Amiri, A., Ghanizadeh, A., et al . Prevalence of Addiction to the Internet, Computer Games, DVD, and Video and Its Relationship to Anxiety and Depression in a Sample of Iranian High School Students. (2014) IJPBS 8(2): 75-80.

15. Khademalhosseini, Z., Ahmadi, J., Khademalhosseini, M. Prevalence of Smoking, and its Relationship with Depression, and Anxiety in a Sample of Iranian High School Students. (2015) Enliven: Pharmacovigil Drug Saf 1(1): 005.

16. Ahmadi, J. The Effect of Buprenorphine and Bupropion in the Treatment of Methamphetamine Dependency and Craving.( 2015) Br J Med \& Med Res 10(2): 1-3.

17. Ahmadi, J., Dehghanian, I., RazeghianJahromi, L. Poly substance induced psychosis. (2015) Sch. J. App. Med. Sci 3(7D): 2693-2695.

18. Ahmadi, J., Dehghanian, I., RazeghianJahromi, L. Substance induced disorder. (2015) Sch. J. App. Med. Sci., 3(7D): 2700-2703.

19. Ahmadi,J. Tramadol Dependency Treatment: A New Approach. (2015) J Addict Med Ther Sci 2(1): 1-3.

20. Hoffman, W.F., Moore, M., Templin, R., et al. Neuropsychological function and delay discounting in methamphetamine-dependent individuals. (2006) Psychopharmacology 188(2): 162-170.

21. Salo, R., Nordahl, T.E., Natsuaki, Y., et al. Attentional control and brain metabolite levels in methamphetamine abusers. (2007) Biol Psychiatry 61(11): 1272-1280.

22. Taylor, M. Indications for electroconvulsive therapy. In R Abrams, W Essman, eds. Electroconvulsive Therapy: Biological Foundations and Clinical Applications. (1982) Spectrum Publications 7-40.

23. Kramp, P., Bolwig, T. Electroconvulsive therapy in acute delirious states. (1981) Compr Psychiary 22(4): 368-371.

24. Ahmadi, J., Pridmore, S., Ekramzadeh, S. Successful Use Of Electro Convulsive Therapy In The Management Of Methamphetamine Induced Psychosis With Onset During Intoxication. (2015) J Addict \& Depend 1(1): 12.

25. Ahmadi, J., Sahraian, A., Dastgheib, S.A., et al. Management of MethamphetamineInduced Psychosis by 8 sessions of ECT. (2015) SJAMS 3(3H): 15651566.

26. Ahmadi, J., Sahraian, A., Dastgheib, S.A., et al. ECT and methamphetamine psychosis (2015) IJMPS 7(1): 51-53.

ISSN no: 2471-061X

E-mail: addiction.depend@ommegaonline.org

Website: www.ommegaonline.org 